\title{
Synthesis and structural studies of nickel complex supported by-ONNO-tetra dentate Schiff-base ligand: efficient catalysts for oxidation of phenol
}

\author{
Alekha Kumar Sutar ${ }^{1, ~ *, ~ Y a s o b a n t a ~ D a s ~}{ }^{2}$, Sasmita Pattnaik ${ }^{1}$, Nibedita Nath ${ }^{1}$, Prasanta Rath ${ }^{2}$, \\ Tungabidya Maharana ${ }^{3}$
}

${ }^{1}$ Catalysis Research Lab, Department of Chemistry, Ravenshaw University, Cuttack-3, Odisha, India

${ }^{2}$ School of Applied Sciences (Chemistry), KIIT University, Bhubaneswar, Odisha, India

${ }^{3}$ Department of Chemistry, National Institute of Technology, Raipur, India

\section{Email address:}

dralekhasutar@gmail.com(A. K. Sutar)

\section{To cite this article:}

Alekha Kumar Sutar, Yasobanta Das, Sasmita Pattnaik, Nibedita Nath, Prasanta Rath, Tungabidya Maharana. Synthesis and Structural Studies of Nickel Complex Supported by-ONNO-Tetra Dentate Schiff-Base Ligand: Efficient Catalysts for Oxidation of Phenol. International Journal of Materials Science and Applications. Vol. 2, No. 4, 2013, pp. 136-145. doi: 10.11648/j.ijmsa.20130204.13

\begin{abstract}
The free and polymer anchored complex of nickel [3-MHBdMBn-Ni and P-3-MHBdMBn-Ni], supported by -ONNO-tetradentate Schiff-base ligand are prepared by the reactions of nickel solution with one molar equivalent of unsupported 3-MHBdMBn (N, N'-bis (2-hydroxy-3-methylbenzaldehyde) 4-Methylbenzene-1,2-diamine) or polymer supported (P-3-MHBdMBn) Schiff-base ligands in methanol. The structural study reveal that nickel (II) complex of 3-MHBdMBn Schiff base is square planar in geometry. Complexation of nickel ion increased the thermal stability of 3-MHBdMBn Schiff base. The catalytic activity of nickel complex towards the oxidation of phenol is investigated in the presence of hydrogen peroxide. Experimental results indicate that the reactivity of P-3-MHBdMBn-Ni is dramatically affected by the polymer support over 3-MHBdMBn-Ni and the rate of oxidation $\left(\mathrm{R}_{\mathrm{p}}\right)$ for unsupported one is $1.28 \times 10^{-6}$ mole $\mathrm{dm}^{-3} \mathrm{~s}^{-1}$ and for supported analogue is $1.99 \times 10^{-6}$ mole $\mathrm{dm}^{-3} \mathrm{~s}^{-1}$.
\end{abstract}

Keywords: Schiff Base, Polymer Support, Catalysis, Nickel, Phenol, Oxidation

\section{Introduction}

Various metal ions and their complexes have been used widely in homogeneous catalyzed reactions but inherent disadvantages associated with homogeneous catalysis were minimized by using supported metal complexes, which sometime have shown high catalytic activities in comparison to unsupported analogues. The supported catalysts are easily recovered without any substantial loss in their catalytic activity [1-2] but homogeneous catalysts are not recovered easily. The Schiff base complexes of transition metal ions shown high catalytic activities in various chemical reactions such as epoxidation of olefins,[3] oxidation,[4-5] and polymerization of ethylene,[6-7] but polymer-supported metal complexes showed high catalytic activity [4,5,8-10], in comparison to homogeneous catalysts. The manganese(II) salen complexes anchored on tailor-made polymers were more enantioselective without any mass transfer limitation for alkenes on polymer supports.[11] The transition metal complexes were also anchored on other supports,[12-15] and have been used in selective oxidation of phenols but oxidation of phenol using metal salen complexes on polymer supports found to be more efficient and selective in comparison to homogeneous systems, as the polymeric supports provided better control on efficiency of catalysts [8] due to microenvironment provided by polymer chains for the substrates in comparison to zeolites [16] and silica.[17] The metal complexes on solid supports are immobilized either physically or by forming a covalent bond between metal complexes and supports.[8] But the recovery of physically linked catalysts has been found to be low in comparison to covalently bound catalysts due to the leaching of catalysts. The oxidation of phenol using unsupported Schiff base complexes of metal ions is reported,[18] but the oxidation of phenol using polymer-supported transition metal complexes was found to be high [19] in the presence of tert-butyl hydroperoxide (t-BHP). In these investigations, the homogeneous cobalt salen complexes have shown poor 
catalytic activity in comparison to polymer bound cobalt (II) salen complexes. On doubling the concentration of polymer bound catalyst, the conversion of phenol was doubled, whereas in case of homogeneous conditions, the phenol conversion was increased to 1.7 -fold. The activity of metal complexes on polymer supports has normally found to be more in comparison to metal complexes on inorganic supports [20-22]. The polymer-supported Schiff base complexes of metal ions also showed variations in the decomposition of hydrogen peroxide with their redox potentials, [20] which provided a useful criterion to explain the activity of metal ions in the oxidation of phenol in the presence of hydrogen peroxide as the oxidant. The activity of polymer-supported Schiff base complexes of iron(III), cobalt(II) and nickel(II) ions in the oxidation of phenol [21-22] also showed variation with temperature, time, etc, which might be due to the change in concentration of substrate or catalyst. The oxidation of phenol in the presence of metal complexes of salen and hydrogen peroxide as the oxidant is reported, but catalytic activity of metal complexes of N, N'-bis (2-hydroxy-3 -methylbenzaldehyde) 4-Methylbenzene- 1,2-diamine Schiff base (3-MHBdMBn) Schiff base is not reported in the literature; hence, in these investigations an attempt has been made to prepare polymer-supported nickel complex of 3-MHBdMBn Schiff base and to characterize them for their structures and catalytic activity in the oxidation of phenol in the presence of hydrogen peroxide as an oxidant.

\section{Experimental}

\subsection{Materials}

Divinyl benzene cross-linked chloromethylated polystyrene beads were obtained from Ion Exchange India Ltd., Mumbai, India and used to anchor synthesized 3-MHBdMBn Schiff base complexes of metal ions. The anhydrous chloro salts of nickel (II) ions were purchased from Ranbaxy, Mumbai, India and used without further purifications. The phenol, hydrogen peroxide (30.0 wt \%), 2-hydroxy-3-methylbenzaldehyde (3-MHBd) and 4-Methylbenzene-1, 2-diamine (MBn) were procured form E. Merck, India. Other chemicals and solvents were of analytical grade $(>99.0 \mathrm{wt} \%)$ and used after purifications with standard methods. [23]

\subsection{Characterization of 3-Mhbdmbn Schiff Base and Its Metal Complexes}

IR spectra of 3-MHBdMBn Schiff base and its nickel complex were recorded on $\mathrm{KBr}$ pellet using Perkin-Elmer 1600 FTIR Spectrophotometer. The electronic spectra of 3-MHBdMBn Schiff base and its nickel complex were recorded with Shimadzu 1601 PC UV-Vis Spectrophotometer by using sample mull in a cuvette. Thermogravimetric analysis (TGA) of 3-MHBdMBn Schiff base and its nickel complex was carried out using Perkin-Elmer Pyris, Diamond Thermal Analyzer under nitrogen atmosphere at a heating rate of $5^{0} \mathrm{C} \mathrm{min}^{-1}$. The loading of metal ions on 3-MHBdMBn Schiff base was determined by analyzing the loading solution with Perkin-Elmer 3100 Atomic Absorption Spectrometer at $\lambda_{\max }$ of nickel ions. The amount of 3-MHBdMBn Schiff base anchored on polymer beads and its composition were estimated using Haraeus Carlo Ebra 1108 Elemental Analyzer. The ${ }^{1} \mathrm{H}-\mathrm{NMR}$ spectra of 3-MHBdMBn Schiff base and nickel complex were recorded on an FT-NMR-Brucker $300 \mathrm{MHz}$ Spectrometer using DMSO-d ${ }^{6}$ as a solvent and tetramethylsilane (TMS) as an internal reference. The magnetic moment $(\mu)$ of nickel complex was measured using Vibrating Sample Magnetometer-155. The molecular weight of 3-MHBdMBn Schiff base and its nickel complex was determined using a Vapor Pressure Osmometer (Merk VAPRO 5600, Germany).

\subsection{Synthesis of N, N'-Bis (2-Hydroxy- 3-Methylbenzaldehyde) 4-Methylbenzene-1, 2 -Diamine Schiff Base (3-Mhbdmbn) and Its Metal Complexes}

The 3-MHBdMBn Schiff base was synthesized modifying the procedure reported in the literature.[21] The reaction mixture containing 2-hydroxy-3 -methylbenzaldehyde (20.00 mmol, $2.72 \mathrm{~g})$ and 4-Methylbenzene-1,2-diamine (10.00 mmol, $1.22 \mathrm{~g})$ in methanol was refluxed at $60^{\circ} \mathrm{C}$ for about $1 \mathrm{hr}$. The reaction mixture on cooling at low temperature produced light orange colored crystals, which were iltered and recrystallized with methanol. The metal complexes of 3-MHBdMBn Schiff base were prepared taking $100 \mathrm{ml}$ methanolic solution of mixture of Schiff base $(20.00 \mathrm{mmol}$, $7.16 \mathrm{~g}$ ) and $20.00 \mathrm{mmol}$ of metal ions in a round bottom flask and refluxing at $60^{\circ} \mathrm{C}$. After $8 \mathrm{~h}$, the solution was cooled and crystalline metal complexes were separated from the mother liquor. Finally, metal complexes were recrytallized in methanol and dried in a vacuum desiccator.

\subsection{Synthesis of Polymer-Anchored N, $N^{\prime}$-Bis (2-Hydroxy-3-Methylbenzaldehyde) 4-Methylbenzene-1, 2 -Diamine Schiff Base and Its Nickel Complex}

To prepare polymer-anchored nickel complex of 3-MHBdMBn Schiff base, the N, N'-bis (4-amino-2-hydroxy-3-methylbenzaldehyde)

4-Methylbenzene-1,2-diamine (A-3-MHBdMBn) Schiff base was prepared by carrying out nitrosation and reduction reactions on 3-MHBdMBn Schiff base and then reacting resulted A-3-MHBdMBn Schiff base with cross-linked chloromethylated polystyrene beads. The nitrosation of 3-MHBdMBn Schiff base was carried out using 20.00 mmol (7.16 g) of 3-MHBdMBn Schiff base with sodium nitrite $(20.00 \mathrm{mmol})$ in $1.0 \mathrm{~N}$ hydrochloric acid $(100 \mathrm{ml})$ at $-5^{0} \mathrm{C}$. The resultant $\mathrm{N}$, N'-bis (4-nitroso2-hydroxy-3-methylbenzaldehyde) 4-Methylbenzene -1,2-diamine (NO-3-MHBdMBn) was filtered and washed 
with hot and cold water to remove reaction impurities. The reduction of NO-3-MHBdMBn was carried out using 20.00 mmol of nitrosated Schiff base in $1.0 \mathrm{~N}$ hydrochloric acid $(50 \mathrm{ml})$ in the presence of metallic iron, which produced A-3-MHBdMBn Schiff base. To immobilize the prepared A-3-MHBdMBn Schiff base on cross-linked chloromethylated polystyrene, the methanol swollen polymer beads $(5.0 \mathrm{~g})$ were refluxed in $50 \mathrm{ml}$ methanol containing $20.00 \mathrm{mmol}$ (7.76 g) A-3-MHBdMBn Schiff base. After $8 \mathrm{~h}$, the 3-MHBdMBn Schiff base-anchored polymer beads were separated and dried in a vacuum desiccator. The amount of 3-MHBdMBn Schiff base loaded on polymer beads was estimated with elemental analysis. Subsequently, the metal ions were loaded by keeping 3-MHBdMBn loaded polymer beads $(5.0 \mathrm{~g})$ for $10 \mathrm{~h}$ in an aqueous solution $(50 \mathrm{ml})$ of metal ions $(20.00 \mathrm{mmol})$. Finally, the polymer beads were separated and dried at $70^{\circ} \mathrm{C}$ in a vacuum oven after washing with hot and cold water. The loading of nickel ion on polymer bead was determined by analyzing the loading solution with an Atomic Absorption Spectrometer. The loading of nickel ion on free and polymer-supported 3-MHBdMBn Schiff base was calculated as complexation of nickel ion using the amount of 3-MHBdMBn Schiff base taken initially and the amount of nickel ion loaded on polymer beads.

Complexation of metal ions $=$

$$
\frac{\text { Amount of nickel ion loaded }}{\text { Amount of Schiff base used for loading }} \times 100
$$

\subsection{Catalytic Activity of Metal Complexes in Oxidation of Phenol}

To evaluate the catalytic activity of free and polymersupported nickel complex of 3-MHBdMBn Schiff base, the oxidation of phenol was carried out using hydrogen peroxide as the oxidant at fixed ionic strength $(0.10 \mathrm{M})$ and hydrogen ions concentration $(\mathrm{pH}$ 7.0) in the reaction mixture. To carry out these reactions, a calculated amount of metal-anchored polymer beads was taken in a two-necked round-bottomed flask containing $0.05 \mathrm{M}$ phenol (4.70 g). The oxidation of phenol was carried out adding $5.67 \mathrm{~g}(0.05 \mathrm{M})$ hydrogen peroxide $(30.0 \mathrm{wt} \%)$ in the reaction mixture and $2.0 \mathrm{ml}$ chlorobenzene as an internal standard. The water condenser and supply of nitrogen were attached with reaction flask before starting the heating and stirring (1200 rpm) of reaction mixture. Gas chromatography was used to follow these reactions at different time intervals. The retention time of standards was used to identify the reaction products, and product selectivity was measured using peak areas of reaction products in the chromatograms. The reactions were also carried out taking different molar ratios of substrates, hydrogen peroxide, and catalyst. The rate of oxidation for the oxidation of phenol was determined by studying reactions at different temperatures at constant molar ratios of substrate to $\mathrm{H}_{2} \mathrm{O}_{2}$ and catalyst. The reactions were also studied without using catalysts to analyze the effect of catalyst in the oxidation of phenol.

\section{Results and Discussion}

Investigations have revealed that polymer-supported metal complexes are sometimes more catalytic and efficient than free and unsupported analogs. [19-20] the activity of catalysts also showed dependence on properties of polymer supports and amount of loaded catalysts. Thermal stability of catalysts is required to be high, if these catalysts have to be applied in high temperature reactions. Therefore, thermal analysis of supported metal complexes was carried out to evaluate their possible applications in high temperature reactions and to provide a proof for complexation of metal ions with polymer-anchored 3-MHBdMBn Schiff base. The TGA of polymer supported 3-MHBdMBn Schiff base showed a weight loss of 40.4 wt $\%$ at $500^{\circ} \mathrm{C}$, but its nickel(II) ion complex showed a weight loss of $36.5 \mathrm{wt} \%$ at same temperature, which was clear indication that nickel(II) ion complex was more stable than Schiff base (Figure 1).

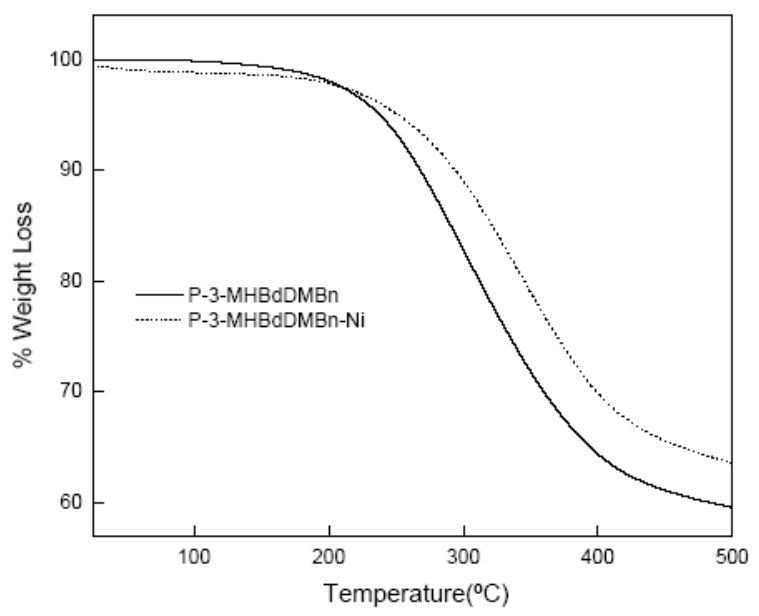

Figure 1. Thermal stability of polymer-supported 3-MHBdMBn Schiff base and its nickel complex

In addition to thermal analysis, the free and polymer-supported nickel complex of 3-MHBdMBn Schiff base was also characterized by IR and UV techniques to provide a proof for the complexation of metal ions and to decide the structures and geometry of complex on the basis of elemental analysis and magnetic properties.

\subsection{Characterization Of $N$, N'-Bis (2-Hydroxy- 3-Methylbenzaldehyde) 4-Methylbenzene-1, 2 -Diamine (3-Mhbdmbn) Schiff Base}

The 3-MHBdMBn Schiff base was obtained by refluxing 2-hydroxy-3-methylbenzaldehyde (3-MHBd) and 4-Methylbenzene-1, 2-diamine (MBn) for $1 \mathrm{hr}$ at $60^{\circ} \mathrm{C}$ in methanol, which produced a substantial yield (86.2 wt \%) of 3-MHBdMBn Schiff base (Scheme 1). The IR spectrum (Figure 2) of 3-MHBdMBn Schiff base showed absorption 
bands at $1610 \mathrm{~cm}^{-1}(>\mathrm{C}=\mathrm{N}), 1268 \mathrm{~cm}^{-1}(>\mathrm{C}-\mathrm{O})$ phenolic (Figure 2A) and a broad band between 3350 and $2910 \mathrm{~cm}^{-1}$ was also observed, which was assigned to phenolic $\mathrm{OH}$. The elemental analysis of 3-MHBdMBn Schiff base showed (wt \%): $\mathrm{C}=76.64, \mathrm{~N}=8.06$ and $\mathrm{H}=5.79$; Caltd $(\%): \mathrm{C}=77.07, \mathrm{~N}=7.82$ and $\mathrm{H}=6.19$, which corresponded to $\mathrm{C} 23 \mathrm{H} 22 \mathrm{~N} 2 \mathrm{O} 2$ empirical formula of 3-MHBdMBn Schiff base.

The molecular weight of Schiff base was $357.37 \mathrm{~g} \mathrm{~mol}^{-1}$ (Caltd $358.43 \mathrm{~g} \mathrm{~mol}^{-1}$ ). The electronic spectra of 3-MHBdMBn Schiff base (Figure 3) showed absorption bands at $284 \mathrm{~nm}$ and $346 \mathrm{~nm}$, which were assigned to $\pi \rightarrow$ $\pi^{*}$ and $\mathrm{n} \rightarrow \pi^{*}$ transitions. The 1H-NMR spectrum of HPPn Schiff base showed signals at $\delta / \mathrm{ppm}=2.52(6 \mathrm{H}), 2.83(3 \mathrm{H})$, $5.15(2 \mathrm{H}), 6.91(2 \mathrm{H}), 7.27(2 \mathrm{H}), 7.41(3 \mathrm{H}), 7.60(2 \mathrm{H})$, and $8.66(2 \mathrm{H})$ which corresponded to the structure of 3-MHBdMBn Schiff base as shown in Scheme 1.

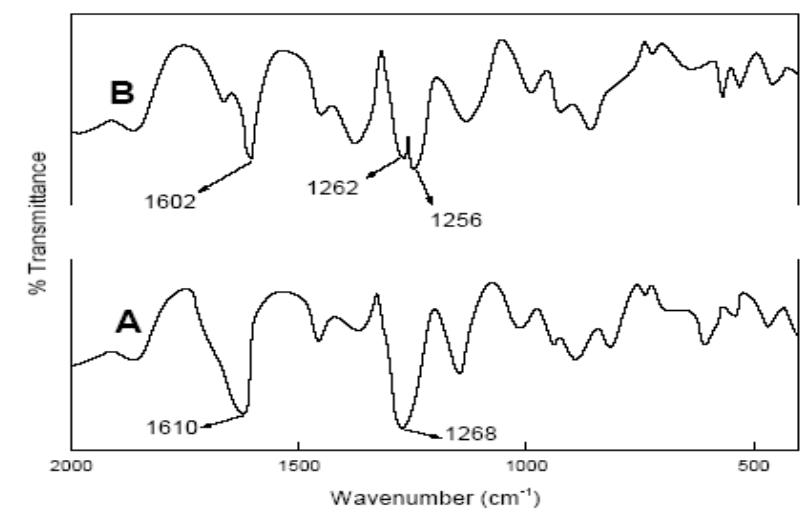

Figure 2. FTIR spectra of unsupported 3-MHBdDMBn Schiff base (A) and polymer supported 3-MHBdDMBn Schiff base (B)

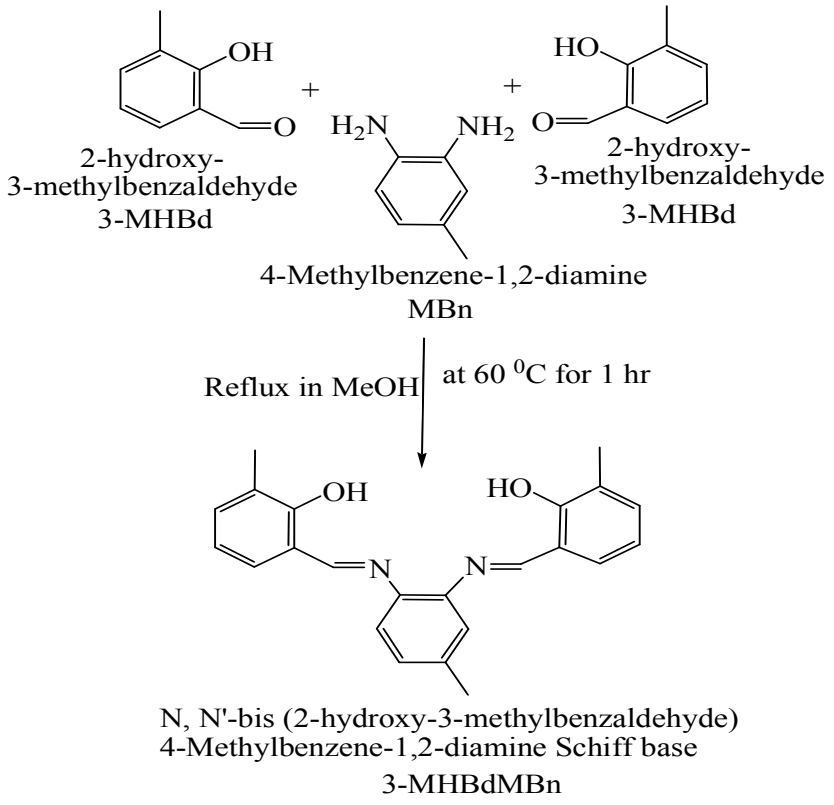

Scheme 1. $N$, N'-bis (2-hydroxy-3- methylbenzaldehyde) 4-Methylbenzene -1,2-diamine (3-MHBdMBn) Schiff base

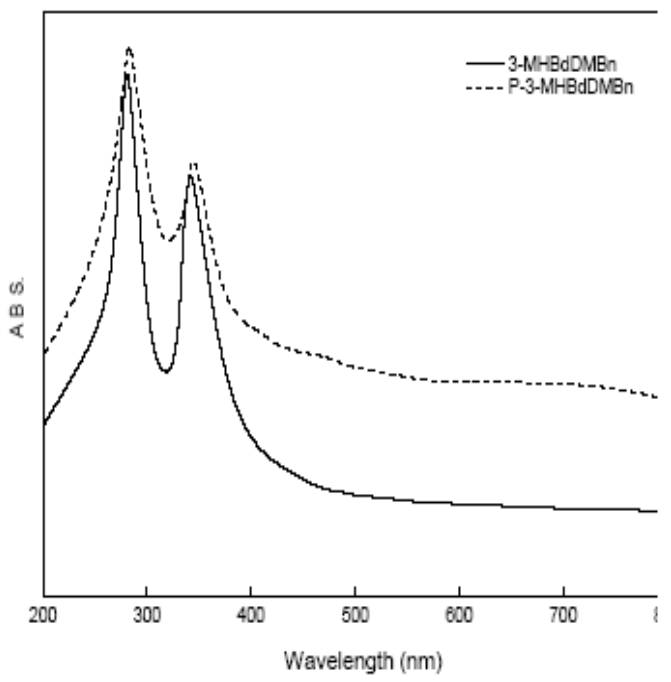

Figure 3. Electronic spectra of unsupported and polymer supported 3-MHBdDBn Schiff base

\subsection{Synthesis and Characterization Of $N, N^{\prime}-B i s$ (4-Amino-2-Hydroxy-3-Methylbenzaldehyde) 4-Methylbenzene -1, 2 -Diamine (A-3-Mhbdmbn) Schiff Base And Its Anchoring On Polymer Beads}

The nitrosation of 3-MHBdMBn Schiff base was carried out in the presence of $\mathrm{NaNO}_{2} / \mathrm{HCl}$, which gave $86.5 \%$ yield of N, N'-bis (4-nitroso-2-hydroxy-3-methylbenzaldehyde) 4-Methylbenzene-1,2-diamine (NO-3-MHBdMBn) (Scheme 2). The elemental analysis of $\mathrm{N}, \mathrm{N}$-bis (4-nitroso-2-hydroxy-3-methylbenzaldehyde)

4-Methylbenzene-1, 2-diamine showed (wt \%): $\mathrm{C}=67.00$, $\mathrm{N}=12.63$, and $\mathrm{H}=5.00$; Caltd (wt \%): $\mathrm{C}=66.34, \mathrm{~N}=$ 13.45 , and $\mathrm{H}=4.84$, which corre- sponded to $\mathrm{C}_{23} \mathrm{H}_{20} \mathrm{~N}_{4} \mathrm{O}_{4}$ formula of nitrosated Schiff base. The molecular weight of NO-3-MHBdMBn was $415.03 \mathrm{~g} \mathrm{~mol}^{-1}$ (Caltd $416.43 \mathrm{~g}$ $\left.\mathrm{mol}^{-1}\right)$. The IR spectrum of NO-3-MHBdMBn showed absorption bands at $1607 \mathrm{~cm}^{-1}(>\mathrm{C}=\mathrm{N}), 1266 \mathrm{~cm}^{-1}$ $\left(>\mathrm{C}-\mathrm{O}\right.$ )phenolic, and $1530 \mathrm{~cm}^{-1}$ and $1320 \mathrm{~cm}^{-1}$ for $\mathrm{N}-\mathrm{O}$ group. The nitrosation of 3-MHBdMBn Schiff base showed a shift in NMR signals in comparison to NMR signals observed with pure 3-MHBdMBn Schiff base. The nitrosated 3-MHBdMBn Schiff base showed proton signals at $\delta / \mathrm{ppm}=2.54(6 \mathrm{H}), 2.88(3 \mathrm{H}), \quad 5.15(2 \mathrm{H}), \quad 7.35(2 \mathrm{H})$, 7.42(3H), 7.96(2H), and $8.69(2 \mathrm{H})$, which corresponded to the structure of nitrosated 3-MHBdMBn Schiff base as shown in Scheme 2. The protons ortho to nitroso group in 3-MHBdMBn Schiff base were deshielded; hence, their signals appeared at 7.35 and $7.96 \mathrm{ppm}$ in place of 7.27 and $7.60 \mathrm{ppm}$ respectively, of pure 3-MHBdMBn Schiff base. The proton signal at $6.91 \mathrm{ppm}$ was missing due to the substitution of nitroso group in the benzene. The NO-3-MHBdMBn was reduced with iron (III) ions in the presence of hydrochloric acid, which gave $81.3 \mathrm{wt} \%$ yield of A-3-MHBdMBn Schiff base as shown in Scheme 2. The A-3-MHBdMBn Schiff base was characterized. The elemental analysis of A-3-MHBdMBn Schiff base showed (wt\%): $\mathrm{C}=70.54, \mathrm{~N}=13.00$, and $\mathrm{H}=7.02$, Caltd (wt\%): $\mathrm{C}$ 
$=71.11, \mathrm{~N}=14.42$, and $\mathrm{H}=6.23$, which corre- sponded to $\mathrm{C}_{23} \mathrm{H}_{24} \mathrm{~N}_{4} \mathrm{O}_{2}$ empirical formula of Schiff base. The molecular weight of A-3-MHBdMBn Schiff base was found to be $387.23 \mathrm{~g} \mathrm{~mol}^{-1}$ (Caltd $388.46 \mathrm{~g} \mathrm{~mol}^{-1}$ ). The IR spectrum of A-3-MHBdMBn Schiff base showed absorption bands at $1605 \mathrm{~cm}^{-1}(>\mathrm{C}=\mathrm{N}), 1263 \mathrm{~cm}^{-1}$ $\left(>\mathrm{C}-\mathrm{O}\right.$ )phenolic, and a band between 1632 and $1618 \mathrm{~cm}^{-1}$ for $>\mathrm{C}-\mathrm{N}$ group. The 1H-NMR spectrum of A-3-MHBdMBn Schiff base showed proton signals at $\delta / \mathrm{ppm}=2.52(6 \mathrm{H}), 2.85(3 \mathrm{H}), 4.15(4 \mathrm{H}), 5.15(2 \mathrm{H}), 6.36$ $(2 \mathrm{H}), \quad 7.42(3 \mathrm{H}), \quad 6.81(2 \mathrm{H}), \quad$ and $8.69(2 \mathrm{H})$, which corresponded to the structure of A-3-MHBdMBn Schiff base as shown in Scheme 2.

The synthesized A-3-MHBdMBn Schiff base was anchored on cross-linked chloromethylated polystyrene beads by refluxing A-3-MHBdMBn Schiff base with polymer beads in DMF for $8 \mathrm{~h}$ at $60^{\circ} \mathrm{C}$. The amount of A-3-MHBdMBn Schiff base anchored on polymer beads was $87.0 \quad \mathrm{wt}^{\mathrm{O}} \%$ (Scheme 3 ). The anchoring of A-3-MHBdMBn Schiff base on polymer beads was confirmed by comparing the IR spectrum of 3-MHBdMBn Schiff base anchored polymer beads with IR spectrum of pure polymer beads. The IR spectrum of polymer-anchored Schiff base showed new absorption bands at $1602 \mathrm{~cm}^{-1}$ $(>\mathrm{C}=\mathrm{N}), 1260 \mathrm{~cm}^{-1}(>\mathrm{C}-\mathrm{O})$ phenolic, and a broadband between 1629 and $1610 \mathrm{~cm}^{-1}(>\mathrm{C}=\mathrm{N})$, which were absent in the IR spectrum of pure polymer beads, but were present in free Schiff base. The IR spectrum of pure polymer beads showed absorption band at $1262 \mathrm{~cm}^{-1}$, which is attributed to $\mathrm{C}-\mathrm{Cl}$ bond of chloromethyl in cross-linked polymer beads. The decrease in the intensity of absorption band at 1262 $\mathrm{cm}^{-1}$ in polymer- anchored 3-MHBdMBn Schiff base than pure polymer beads was an evidence for anchoring of 3-MHBdMBn Schiff base on polymer beads. The appearance of new absorption bands and shift in characteristic absorption bands of 3-MHBdMBn Schiff base were also used as evidence for anchoring of 3-MHBdMBn Schiff base on polymer beads.

\subsection{Characterization of Free and Polymer-Anchored Metal Complexes of 3-Mhbdmbn Schiff Base}

The loading of nickel ion on free and polymer-supported 3-MHBdMBn Schiff base was carried out by refluxing free Schiff base (Scheme 4) and polymer-anchored Schiff base in solution of metal salt at $60^{\circ} \mathrm{C}$ for $6 \mathrm{~h}$ (Scheme 5). The metal complexes of free Schiff base (3-MHBdMBn-Ni) and polymer-anchored Schiff base (P-3-MHBdMBn -Ni) after separation and purification were analyzed for their structures and loading of nickel ion. The complexation of nickel(II) ion on free 3-MHBdMBn Schiff base and polymer-anchored Schiff base was 85.62 and $86.88 \mathrm{wt} \%$ respectively (Table 1). These results have clearly suggested that the loading of nickel ion on polymer-supported 3-MHBdMBn Schiff base was higher than free 3-MHBdMBn Schiff base.
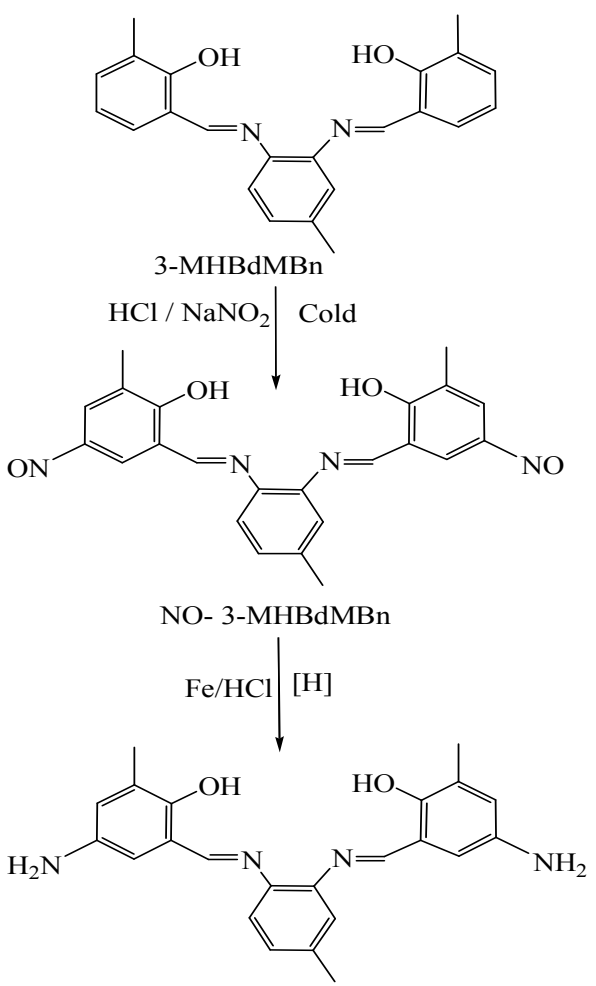

A - 3-MHBdMBn

Scheme 2. Synthesis of $N$, N'-bis (4-amino-2-hydroxy-3methylbenzaldehyde) 4-Methylbenzene-1,2-diamine (A-3-MHBdMBn) Schiff base

Table1. Efficiency of complexation (EC) of nickel ion (wt \%)

\begin{tabular}{cc}
\hline Schiff base & $\begin{array}{c}\text { Complexation (EC) of nickel(II) } \\
\text { ion (wt } \%)\end{array}$ \\
\hline $\begin{array}{c}\text { Unsupported 3-MHBdMBn Schiff } \\
\text { base }\end{array}$ & 85.62 \\
$\begin{array}{c}\text { Polymer supported 3-MHBdMBn } \\
\text { Schiff base }\end{array}$ & 86.88 \\
\hline
\end{tabular}

[3-MHBdMBn] $=20 \mathrm{mmol},[$ Nickel ion $]=20 \mathrm{mmol}$<smiles>Cc1ccc(/N=C/c2cc(N)cc(C)c2O)c(/N=C/c2cc(N)cc(C)c2O)c1</smiles>

A - 3-MHBdMBn

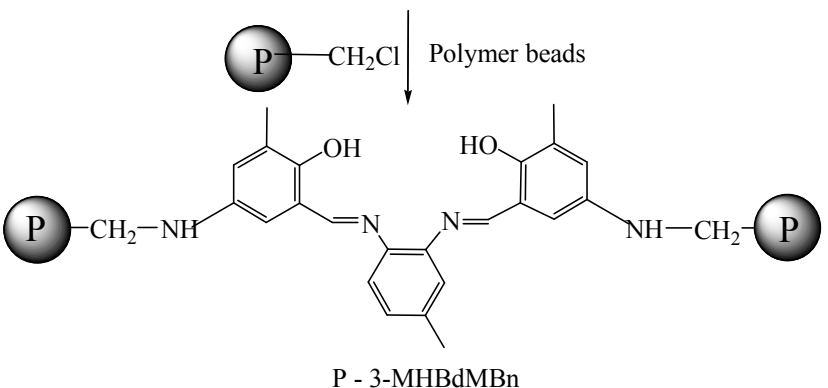

Scheme 3. Synthesis of polymer-anchored Schiff base (P-3-MHBdMBn) 
<smiles>Cc1ccc(N=Cc2cccc(C)c2O)c(N=Cc2cccc(C)c2O)c1</smiles>

3-MHBdMBn

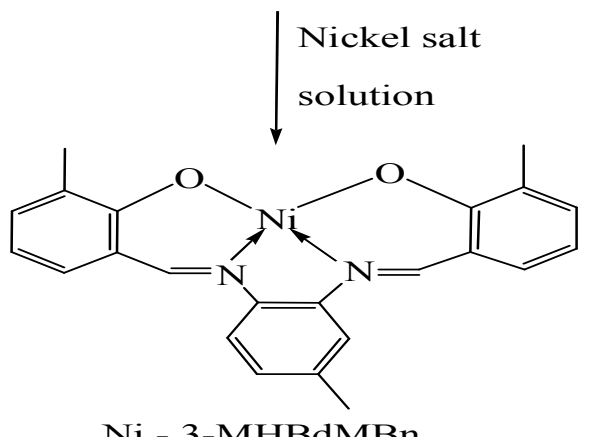

Ni - 3-MHBdMBn

Scheme 4. Loading of nickel ion on unsupported 3-MHBdMBn Schiff base

The complexation of nickel ion with 3-MHBdMBn Schiff base showed significant variations in IR bands for $>\mathrm{C}=\mathrm{N}$ and $>\mathrm{C}-\mathrm{O}$ groups and new absorptions bands appeared due to the formation of $\mathrm{M}-\mathrm{O}$ and $\mathrm{M}-\mathrm{N}$ bonds in metal complex. The disappearance of phenolic absorption band between 2910 and $3350 \mathrm{~cm}^{-1}$ in the IR spectrum of 3-MHBdMBn Schiff base after the complexation of nickel ion was an evidence for the complexation of metal ions with 3-MHBdMBn Schiff base. The polymer-supported Schiff base showed absorption bands at low frequency (Figure 2B) in comparison to free Schiff base (Figure 2A). On complexation with nickel(II) ion, the frequency of $>\mathrm{C}=\mathrm{N}$ absorption band of free Schiff base has decreased from 1610 to $1598 \mathrm{~cm}^{-1}$, whereas polymer- supported Schiff base showed variation from 1602 to $1594 \mathrm{~cm}^{-1}$ (Figure 4).

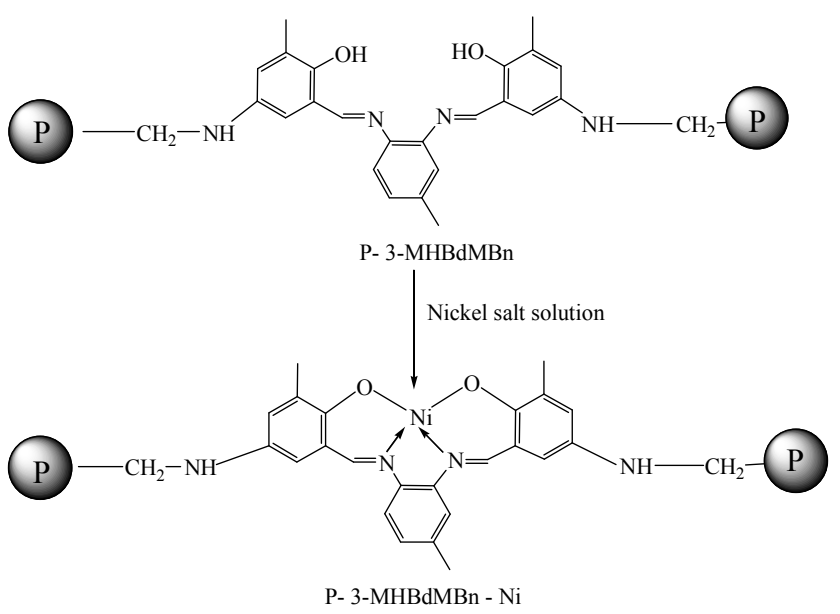

Scheme 5. Loading of nickel ion on polymer-supported Schiff base (P-3-MHBdMBn -Ni)

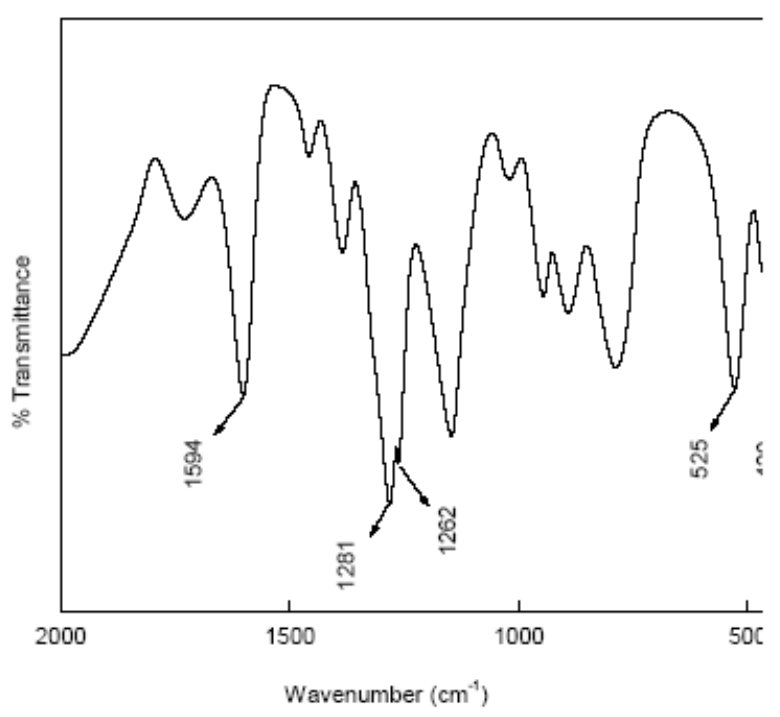

Figure 4. FTIR spectra of polymer supported 3-MHBdDBn-Ni complex

These variations in IR band corresponding to $>\mathrm{C}=\mathrm{N}$ group of 3-MHBdMBn Schiff base were used as evidence for interactions of metal ions with azomethine nitrogen $(>\mathrm{C}=\mathrm{N})$ of 3-MHBdMBn Schiff base. The complexation of nickel(II) ions showed new absorption band at $424 \mathrm{~cm}^{-1}$ with free Schiff base and at $420 \mathrm{~cm}^{-1}$ with polymer-anchored Schiff base, which was due to the formation of $\mathrm{M}-\mathrm{N}$ bond between nickel(II) ion and Schiff base. The complexation of nickel(II) ion showed another new band due to the formation of bond between nickel and phenolic oxygen $(-\mathrm{O}-\mathrm{M})$ with polymer-supported 3-MHBdMBn Schiff base at $525 \mathrm{~cm}^{-1}$ (Figure 4). The complexation of metal ions with Schiff base was further confirmed by comparing electronic spectra of nickel complex and pure 3-MHBdMBn Schiff base. The complexation of nickel(II) ion with 3-MHBdMBn Schiff base showed variation in $\pi \rightarrow \pi^{*}$ transition from $284 \mathrm{~nm}$ to $273 \mathrm{~nm}$ and (Table 2) the $\mathrm{n} \rightarrow \pi{ }^{*}$ transition of 3-MHBdMBn Schiff base was changed from $346 \mathrm{~nm}$ to 295 $\mathrm{nm}$. The charge transfer $(\mathrm{CT})$ and $\mathrm{d} \rightarrow \mathrm{d}$ transitions were also used as evidence for complexation of nickel with Schiff base. These electronic transitions corresponded to $\mathrm{t}_{2 \mathrm{~g}}{ }^{6} \mathrm{e}_{\mathrm{g}}{ }^{2}$ configurations for nickel(II) ion in this complex.

Table2. Electronic transitions in unsupported and polymer supported nickel complex of 3-MHBdMBn Schiff base

\begin{tabular}{|c|c|c|c|c|}
\hline \multirow{2}{*}{ Compounds } & \multicolumn{4}{|c|}{ Frequencies $\lambda_{\max } / \mathbf{n m}$} \\
\hline & $\pi \rightarrow \pi *$ & $\mathrm{n} \rightarrow \pi *$ & $\mathrm{C} \rightarrow \mathrm{T}$ & $d \rightarrow d$ \\
\hline 3-MHBdMBn & 284 & 346 & - & 459 \\
\hline P-3-MHBdMBn & 281 & 341 & - & 451 \\
\hline 3-MHBdMBn -Ni & 273 & 295 & 312 & 399 \\
\hline P-3-MHBdMBn -Ni & 268 & 288 & 307 & 396 \\
\hline
\end{tabular}


<smiles>Cc1ccc2c(c1)N1Cc3cccc(C)c3ON1Cc1cccc(C)c1O2</smiles>

Ni- 3-MHBdMBn (Square planar)

Scheme 6. Geometry and structure of 3-MHBdMBn Schiff base complex of nickel ion.

The magnetic moment $(\mu)$ of nickel Schiff base complex was found to be $0.93 \mathrm{BM}$, which indicated that nickel(II) ion complex was diamagnetic in nature with zero unpaired electron. The magnetic moment $(\mu)$ and electronic configurations have suggested a square planar structure with dsp ${ }^{2}$ hybridization for nickel complex (Scheme 6).

\subsection{Oxidation of Phenol}

The catalytic activity of free and polymer-supported nickel complex of 3-MHBdMBn Schiff base was evaluated by studying the oxidation of phenol in the presence of hydrogen peroxide. The gas chromatographic analysis was used to determine the product selectivity and to estimate the percent conversion of phenol. The catechol (CTL) was a major reaction product in the oxidation of phenol (Scheme 7). The formation of reaction products was attributed to enzymatic behaviour of metal complexes of 3-MHBdMBn Schiff base.<smiles>Oc1ccc(-c2ccc(O)c(O)c2)cc1</smiles>

Catechol (CTL) Hydroquinone (HQ)

Scheme 7. oxidation of phenol

The polymer support has facilitated the decomposition of these intermediates; hence, per cent conversion of phenol was more with polymer-supported nickel complex (Figure 5) in comparison to free complex of 3-MHBdMBn Schiff base (Table 3). The conversion of phenol was initially high at $240 \mathrm{~min}$ and then after the conversion became almost constant due to substantial decrease in the concentration of oxidant and substrate in the reaction mixture (Table 3). Similar trends in substrate conversion were observed with supported catalysts at different time intervals as found with unsupported catalysts (Figure $5 \&$ Table 3). The oxidation reaction also showed dependence on type of catalyst. The high activity of metal complexes on polymer support was due to the facile interactions of catalyst with substrate than with unsupported catalysts. The low activity of catalyst in solution was due to the formation of inactive dimers or multimers of metal complexes in the solution. The amount of phenol oxidized with hydrogen peroxide was almost equal to the sum of amount of CTL and hydroquinone (HQ) produced, which discarded the formation of other reaction products such as polymeric phenols.

The amount of CTL and HQ was equal to phenol conversion, but reaction showed high selectivity for CTL. The supported catalysts were recycled and also further evaluated for their catalytic activity after their applications in oxidation reactions. The efficiency of supported catalysts remained almost constant upto six recycles and then the efficiency decreased (Table 4). The product selectivity for CTL remained unaffected on using recycled catalysts, which was an indication for the structural stability of metal complexes on polymer support as confirmed by comparing IR spectra of recycled catalysts with IR spectra of freshly prepared catalysts. The activity of metal complexes in substrate conversion and product selectivity was evaluated at different molar ratios of substrate to hydrogen peroxide and catalyst.

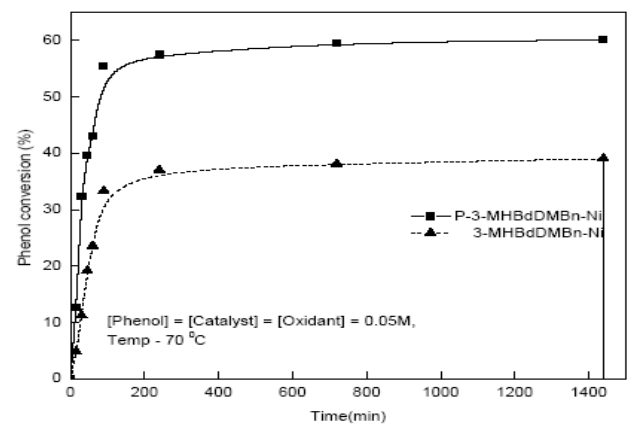

Figure 5. Effect of reaction time on oxidation of phenol in presence of polymer-supported and unsupported nickel complexes [Phenol]:[Catalyst]: $\left[\mathrm{H}_{2} \mathrm{O}_{2}\right]=1: 1: 1(0.05 \mathrm{M})$, Temp. $=70^{\circ} \mathrm{C}$

Table 3. Catalytic activity of unsupported and polymer supported nickel complex (Ni-3-MHBdMBn) in oxidation of phenol (Ph).

\begin{tabular}{ccc}
\hline & Percent conversion (wt\%) of Phenol \\
Time/min & P-3-MHBdMBn-Ni & 3-MHBdMBn-Ni \\
\hline 0 & 0 & 0 \\
15 & 12.6 & 4.8 \\
30 & 32.4 & 11.2 \\
45 & 39.6 & 19.1 \\
60 & 43 & 23.5 \\
90 & 55.4 & 33.3 \\
240 & 57.5 & 37 \\
720 & 58.6 & 38.1 \\
1440 & 60.1 & 39 \\
\hline
\end{tabular}

[Phenol]: [Catalyst]: $\left[\mathrm{H}_{2} \mathrm{O}_{2}\right]=1: 1: 1(0.05 \mathrm{M})$, Temp. $=70{ }^{\circ} \mathrm{C} . \mathrm{CH}_{3} \mathrm{CN}=$ $2.0 \mathrm{~mL}$

Table 4. Efficiency of recycled supported catalysts (P-3-MHBdMBn-M) in oxidation of phenol

\begin{tabular}{cccccccc}
\hline \multicolumn{1}{c}{ Supported metal complexes } & $\mathbf{0}$ & $\mathbf{2}$ & $\mathbf{4}$ & $\mathbf{6}$ & $\mathbf{8}$ \\
\hline \multirow{2}{*}{$\begin{array}{c}\text { P-3-MHBdMBn } \\
\text {-NI }\end{array}$} & $\begin{array}{c}\text { Conversion } \\
\text { Selectivity }\end{array}$ & 60.1 & 60.0 & 59.0 & 57.0 & 41.5 \\
& 94.1 & 93.7 & 94.0 & 91.7 & 89.2 \\
\hline
\end{tabular}

[Phenol]:[Catalyst]: $\left[\mathrm{H}_{2} \mathrm{O}_{2}\right]=1: 1: 1(0.05 \mathrm{M})$, Temp. $=70^{\circ} \mathrm{C} . \mathrm{CH}_{3} \mathrm{CN}=2.0 \mathrm{~mL}$. 
The rate of phenol conversion was high $\left(1.99 \times 10^{-6}\right.$ mole $\left.\mathrm{dm}^{-3} \mathrm{~s}^{-1}\right)$ in the presence of polymer-supported 3-MHBdMBn Schiff base complexes of nickel(II) ion than

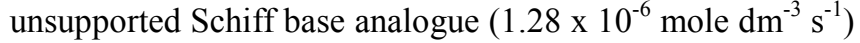
(Table 5). The turnover number (TON) for the oxidation of phenol was high $\left(13.51 \mathrm{~g} \mathrm{~mol}^{-1} \mathrm{Ni} \mathrm{hr}^{-1}\right)$ in the presence of polymer supported Schiff base complex in comparison to unsupported Schiff base complex $\left(8.69 \mathrm{~g} \mathrm{~mol}^{-1} \mathrm{Ni} \mathrm{hr}^{-1}\right)$ at a molar ratio of $1: 1: 1$ of $\mathrm{H}_{2} \mathrm{O}_{2}$ to phenol and catalyst (Table 5). The rate of substrate conversion and TON in the oxidation of phenol varied significantly with molar ratio of hydrogen peroxide but product selectivity in both cases remained almost constant (Tables 5).

Table 5. Oxidation of phenol by nickel complex of 3-MHBdMBn Schiff base: Phenol conversion, selectivity for catechol and kinetic parameters

\begin{tabular}{|c|c|c|c|c|}
\hline Complexes & $\begin{array}{c}\text { Conversion } \\
\text { (wt \%) }\end{array}$ & $\begin{array}{l}\text { Selectivity } \\
\text { (wt \%) }\end{array}$ & TON & $\mathbf{R}_{\mathbf{p}}$ \\
\hline Unsupported catalyst & 39.1 & 93.2 & 8.69 & 1.28 \\
\hline $\begin{array}{l}\text { Polymer-supported } \\
\text { catalyst }\end{array}$ & 60.1 & 94.1 & 13.51 & 1.99 \\
\hline
\end{tabular}

$\left[\mathrm{H}_{2} \mathrm{O}_{2}\right] /[$ Phenol $] /[$ Catalyst $]=0.05 \mathrm{M}$, Time $=1440 \mathrm{~min}$,Temp. $=70{ }^{\circ} \mathrm{C}$ $\mathrm{CH}_{3} \mathrm{CN}=2.0 \mathrm{~mL}$ TON in terms of $=\mathrm{g} \mathrm{mol}^{-1} \mathrm{M} \mathrm{hr}^{-1}$, Rate of oxidation $\left(\mathrm{R}_{\mathrm{p}}\right)$

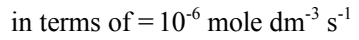

\subsection{Effect of the $\mathrm{H}_{2} \mathrm{O}_{2}$ Concentration / Phenol Concentration /Catalyst Concentration on the Oxidation of Phenol}

The oxidation of phenol was studied with the variation of the molar ratio of $\mathrm{H}_{2} \mathrm{O}_{2}$ to phenol from 0.5 to 2.0 at a constant molarity of the substrate and catalyst $(0.05 \mathrm{M})$ in acetonitrile $(2.0 \mathrm{~mL})$. The reaction temperature was maintained at $70{ }^{0} \mathrm{C}$. When the molar ratio of $\mathrm{H}_{2} \mathrm{O}_{2}$ was varied from 0.5 to 1.0 , the oxidation of phenol increased in the presence of supported 3-MHBdMBn Schiff base complex of nickel(II) (Figure 6). However, when the molar ratio of $\mathrm{H}_{2} \mathrm{O}_{2}$ was further increased $(>1)$ in the reaction mixture, the oxidation of phenol showed a decreasing trend, and a similar trend was observed with unsupported 3-MHBdMBn-Ni Schiff base complex analogue. The decreasing trend in the conversion of phenol was due to the decrease in molar ratio of phenol and catalyst with respect to molar ratio of $\mathrm{H}_{2} \mathrm{O}_{2}$.

The catalytic efficiency of the 3-MHBdMBn Schiff base nickel ion complexes in the oxidation of phenol was evaluated at different molar ratios of phenol in the reaction mixture, whereas the molar ratio of $\mathrm{H}_{2} \mathrm{O}_{2}$ to the catalyst was kept constant. The molar ratio of phenol was varied from 0.5 to 2.0 with respect to the molar ratio of $\mathrm{H}_{2} \mathrm{O}_{2}$ to the catalyst. During the molar ratio variation of phenol, the concentration of $\mathrm{H}_{2} \mathrm{O}_{2}$ and the catalyst was kept constant $(0.05 \mathrm{M})$. When the molar ratio of phenol was increased from 0.5 to 1.0 in the reaction mixture, the conversion (\%) of phenol increased substantially with polymer supported nickel complex of the Schiff base (Figure 6), but when the molar ratio of phenol increased further $(>1)$, the conversion $(\%)$ of phenol showed a decreasing trend, which was due to the significant decrease in the molar ratio of $\mathrm{H}_{2} \mathrm{O}_{2}$ to the catalyst in the reaction mixture in comparison with the molar ratio of phenol.

The oxidation of phenol was also evaluated at different molar ratios of polymer-supported 3-MHBdMBn Schiff base complex of nickel at a constant molar ratio $(1: 1)$ of the substrate and oxidant. The molar ratio of Schiff base complex of nickel(II) ions was varied from 0.5 to 2.0 at a constant molarity $(0.05 \mathrm{M})$ of phenol and $\mathrm{H}_{2} \mathrm{O}_{2}$ in the reaction mixture. The conversion (\%) of phenol also showed the same trend as variation of substrate concentration.

\subsection{Mechanism for Oxidation of Phenol}

Considering the experimental findings for the oxidation of phenol with free and supported 3-MHBdMBn Schiff base complex of nickel ion, the following reaction steps are proposed (Scheme 8). The free and polymer-supported Schiff base complexes of nickel ion (3-MHBdMBn-Ni) have produced active species (Ni-3-MHBdMBn-HOO-) through fast interactions with hydrogen peroxide and 3-MHBdMBn Schiff base. The active species was subsequently used in the formation of intermediates (Ni-3-MHBdMBn-Ph-HOO-) through its interactions with phenol in a rapid equilibrium $(\mathrm{k})$. The intermediate (Ni-3-MHBdMBn-Ph-HOO ${ }^{-}$has facilitated the nucleophilic attack of $\mathrm{OOH}$ species on ortho and para position on phenol to produce hydroxy-substituted phenols (Scheme 7). The reaction products, catalyst and hydroxyl ions were formed through decomposition of intermediates (Scheme 8 step 4) and finally the hydroxyl ions reacted with hydrogen ions, which were produced in step 1 .

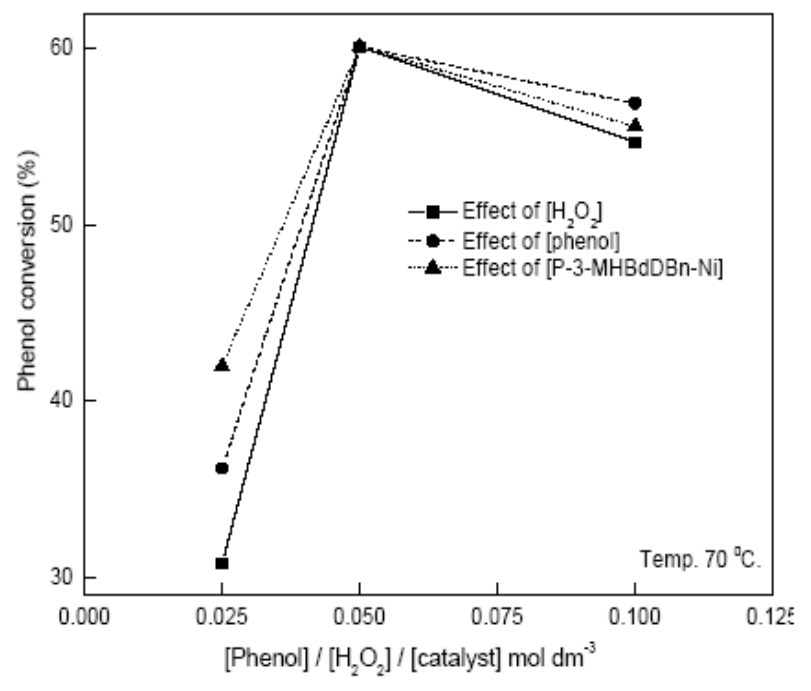

Figure 6. Effect of $\mathrm{H}_{2} \mathrm{O}_{2}$ concentration / phenol concentration /catalyst concentration on oxidation of phenol in presence of polymer-supported nickel complex 


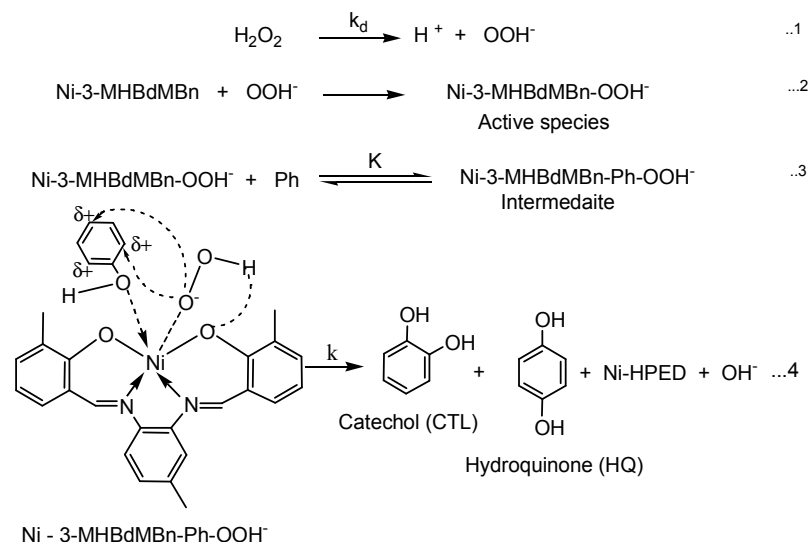

$\mathrm{H}^{+}+\mathrm{HO}^{-} \longrightarrow \quad \mathrm{H}_{2} \mathrm{O}$

Scheme 8. Reaction steps of oxidation of phenol

\section{Conclusion}

The unsupported and polymer-supported nickel complexes of 3-MHBdMBn Schiff base were synthesized and characterized successfully for their structures and catalytic activity in the oxidation of phenol. The polymersupported 3-MHBdMBn Schiff base complexes of nickel ion showed high catalytic activity than free analogue. The oxidation of phenol showed high selectivity for CTL. The supported catalysts showed high rate of oxidation and TON than unsupported catalysts, which clearly suggested that polymer support has played a significant role in increasing the rate for oxidation of phenol in the presence of metal complexes of 3-MHBdMBn Schiff base. Effect of $\mathrm{H}_{2} \mathrm{O}_{2}$ concentration / phenol concentration / catalyst concentration on oxidation of phenol has great role in presence of polymer-supported nickel complex. The oxidation of phenol was maximum at a molar ratio of $1: 1: 1$ molar ratio of phenol to hydrogen peroxide and catalyst.

\section{Acknowledgments}

One of the authors Ms. N. Nath is thankful to UGC, India for providing Fellowship. The authors are also grateful to Ravenshaw University, Cuttack, KIIT University, Bhubaneswar and National Institute of Technology, Raipur for providing research facilities.

\section{References}

[1] Yoo D.W., Han J.H., Nam S.H., Kim H.J., Kim C., Lee J.K., Efficient transesterification by polymer-supported zinc complexes: Clean and recyclable catalysts. Inorg. Chem. Commun. 9 (2006) 654-657.

[2] Yue C., Fei Z., Bitao S., Yupu W., Oxidation of Styrene with Molecular Oxygen Catalyzed by Polymer-Supported O-Aminobenzoic Acid Salicylaldehyde Schiff-Base
Copper(II) Complex. J. Macromol. Sci. Part A Pure Appl. Chem. 43 (6) (2006) 923-931.

[3] Tangestaninejad S, Habibi MH, Mirkhani V, Moghadam M, Grivani G. Simple preparation of some reusable and efficient polymer supported tungsten carbonyl catalysts and clean epoxidation of cis-cyclooctene in the presence of $\mathrm{H}_{2} \mathrm{O}_{2}$. J. Mol. Catal. A: Chem. 2006; 255: 249-253.

[4] Tong J, Zhang Y, Li Z, Xia C. Highly effective catalysts of natural polymer supported salophen $\mathrm{Mn}(\mathrm{III})$ complexes for aerobic oxidation of cyclohexene. J. Mol. Catal. A: Chem. 2006; 249: 47-52.

[5] Gupta KC, Sutar AK, Catalytic activities of Schiff base transition metal complexes. Coord. Chem. Rev. 2008; 252(12-14):1420-1450.

[6] Sutar AK, Maharana T., Dutta S., Chen Chi-Tien, Lin Chu-Chieh, Ring-opening polymerization by lithium catalysts: an overview, Chem. Soc. Rev., 2010, 39, 1724-1746.

[7] Nakayama Y, Bando H, Sonobe Y, Fuzita T. Olefin polymeri- zation behavior of bis (phenoxy-imine) $\mathrm{Zr}$, Ti and $\mathrm{V}$ com- plexes with $\mathrm{MgCl} 2$-based cocatalysts. J. Mol. Catal. A: Chem. 2004; 213: 141-1150.

[8] Gupta KC, Sutar AK, Lin CC, , Polymer supported Schiff base complexes in oxidation reactions. Coord. Chem. Rev.. 2009; 253:1926-1946

[9] Akelah A, Rehab A, Kenawy ER, Zeid MS, Abou MS. Catalytic activity of polymer-montmorillonites in chemical reactions. J. Appl. Polym. Sci. 2006; 101: 1121-1129.

[10] Drago RS, Gaul J, Zombeck A, Straub DK. Preparation and catalytic oxidizing potential of polymer supported chelating amine and Schiff base complexes. J. Am. Chem. Soc. 1980; 102:1033-1038.

[11] Canali L, Cowan E, Gibson CL, Sherrington DC, Delueze H. Remarkable matrix effect in polymer supported Jacobson's alkene epoxidation catalysts. Chem. Commun. 1998; 23: $2501-2508$

[12] Salavati-Niasari M, Salemi P, Davar F. Oxidation of cyclohexene with tert- butylhydroperoxide and hydrogen peroxide catalyzed by $\mathrm{Cu}(\mathrm{II}), \mathrm{Ni}(\mathrm{II}), \mathrm{Co}(\mathrm{II})$, and $\mathrm{Mn}(\mathrm{II})$ complexes of N,N'-bis(a-methylsalicylidene)-2,2-dimethy-2,2-dimethylpr opane-1, 3-diamaine, supported on alumina. J. Mol. Catal. A: Chem. 2005; 238: 215-222.

[13] AlObaidi F, Ye Z, Zhu S. Ethylene polymerization with silica-supported nickel-diimine catalyst: effect of support and polymerization conditions on catalyst activity and polymer properties. Macromol. Chem. Phys. 2003; 204: $1653-1659$.

[14] Casagrande Adriana CA, Tavares Tatiana TdaR, Kuhn Maria Cristina A, Casagrande Osvaldo L, dos Santos Joao HZ, Teranishi T. Tris(pyrazolyl) borate imido vanadium (V) compound immobilized on inorganic supports and its use in ethylene polymerization. J. Mol. Catal. A: Chem. 2004; 212:267-275.

[15] Wang R-M, Zhang Z-L, Lou J-F, Wang Y-P, Song P-F, Xia C-G. Preparation and catalytic oxidation properties of inorganic polymer encapsulated metal complexes. Polym. Adv. Technol. 2004;15: 48-51. 
[16] Fuerte A, Iglesias M, Sanchez F, Corma A. Chiral dioxomolybdenum(VI) and oxovanadium(V) complexes anchored on modified USY-zeolite and mesoporous MCM-41 as solid selective catalyst for oxidation of sulfides or sulfones. J. Mol. Catal A: Chem. 2004; 211: 227-235.

[17] Daniela B, Chiarello SF, Zimnoch dos Santos JH. Effect of MAO silica surface loading on $(\mathrm{nBuCp}) 2 \mathrm{ZeCl} 2$ anchoring on catalyst actvity and on polymer properties. Appl. Catal. A: Gen. 2004; 261: 57-67.

[18] Gupta KC, Sutar AK, Polymer supported catalysts for oxidation of phenol and cyclohexene using hydrogen peroxide as oxidant. Journal of Molecular Catalysis A: Chemical. 2008; 280:173-185.

[19] Owsik I, Kolarz BN, Jezierska J. Oxidation of 2,6-ditertbutylphenols to diphenoquinones catalyzed by sciff base-Cu(II) systems immobolized on polymer support. J.
Catal. Lett. 2006; 107: 197-203.

[20] Wang C, Xin W, Fu X, Zhang Y, Yang Y. Studies on catalytic polarographic hydrogen wave in iridium(IV)-cysteinehydrochloric acid and its application. Fenxi Huaxue 1992; 20: $368-372$.

[21] Gupta KC, Sutar AK, Polymer anchored Schiff base complexes of transition metal ions and their catalytic activities in oxidation of phenol. Journal of Molecular Catalysis A: Chemical. 2007; 272: 64-74.

[22] Gupta KC, Sutar AK, Polymer supported Schiff base complexes of Iron(III), Cobalt(II) and Nickel(II) ions and their catalytic activity in oxidation of phenol and cyclohexane. Journal of Macromolecular Science. Part A: Pure and Applied chemistry.2007; 44:1171-118535.

[23] Vogel AI. Textbook of Practical Organic Chemistry, 1978. ELBS and Longman: London. 